\title{
O turismo de Aracaju/SE em tempos de COVID-19: ameaças e tendências
}

\author{
Tourism in Aracaju/SE in times of COVID-19: threats and trends \\ El turismo de Aracaju/SE en tiempos del COVID-19: amenazas y tendencias
}

Cristiane Alcântara de Jesus Santos

Universidade Federal de Sergipe (UFS), Brasil

cristie09@uol.com.br

Antonio Carlos Campos

Universidade Federal de Sergipe (UFS), Brasil

antonio68@gmail.com

Larissa Prado Rodrigues

Universidade de São Paulo (USP), Brasil

larissa4912@hotmail.com
DOI: https://doi.org/10.18472/cvt.21n3.2021.1983

Redalyc: https://www.redalyc.org/articulo.oa?

$\mathrm{id}=115469516007$

Recepción: 02 Agosto 2021

Aprobación: 05 Noviembre 2021

\section{Resumo:}

Este artigo parte do pressuposto de que o turismo internacional enfrenta uma crise profunda em decorrência da pandemia da COVID-19 que ensejou a paralisia do setor, acarretando prejuízos trilionários. No entanto, seus efeitos se dão desigualmente no espaço-tempo, o que demanda estudos localizados para decifrar as especificidades de seus impactos no turismo de diferentes lugares. Diante disso, este estudo tem como objetivo analisar as implicações no turismo, especificamente, nos serviços turísticos da cidade de Aracaju/SE, a partir das medidas restritivas instituídas com a pandemia. Os procedimentos metodológicos adotados nesta pesquisa exploratória foram o levantamento bibliográfico, a pesquisa documental, bem como entrevistas com agentes públicos e aplicação de formulários com residentes da cidade, com uma abordagem de análise quanti-qualitativa. Os resultados apontam novos desafios postos para o destino no que tange à retomada e atração de fluxos de turistas. Nesse sentido, torna-se urgente a elaboração de propostas criativas e protocolos ajustados no cenário mundial para a reativação das atividades do setor.

Palavras-Chave: Turismo, Pandemia, Aracaju.

\section{Abstract:}

This article assumes that international tourism is facing a deep crisis as a result of the COVID-19 pandemic that brought about the paralysis of the sector, resulting in trillions of losses. However, its effects occur unevenly in space-time, which requires localized studies to decipher the specificities of its impacts on tourism in different places. Therefore, this study aims to analyze the implications on tourism, specifically, on tourism services in the city of Aracaju/SE, from the restrictive measures instituted with the pandemic. The methodological procedures adopted in this exploratory research were the bibliographic survey, the documental research, as well as interviews with public agents and application of forms with city residents, with a quantitative-qualitative analysis approach. The results point to new challenges for the destination with regard to the resumption and attraction of tourist flows. In this sense, it is urgent to prepare creative proposals and protocols adjusted in the world scenario for the reactivation of the sector's activities.

KEYWORDs: Tourism, Pandemic, Aracaju.

\section{Resumen:}

Este artículo asume que el turismo internacional se enfrenta a una profunda crisis producto de la pandemia COVID-19 que provocó la paralización del sector, resultando en billones de pérdidas. Sin embargo, sus efectos ocurren de manera desigual en el espacio-tiempo, lo que requiere de estudios localizados para descifrar las especificidades de sus impactos sobre el turismo en diferentes lugares. Por tanto, este estudio tiene como objetivo analizar las implicaciones sobre el turismo, específicamente, sobre los servicios turísticos de la ciudad de Aracaju/SE, desde las medidas restrictivas instituidas con la pandemia. Los procedimientos metodológicos adoptados en esta investigación exploratoria han sido la revisión bibliográfica, la investigación documental, así como entrevistas a los agentes públicos y aplicación de formularios con vecinos de la ciudad, con un enfoque de análisis cuantitativo- 
cualitativo. Los resultados apuntan a nuevos retos para el destino en cuanto a la reanudación y atracción de flujos turísticos. En este sentido, es urgente elaborar propuestas creativas y protocolos ajustados en el escenario mundial para la reactivación de las actividades del sector.

Palabras clave: Turismo, Pandemia, Aracaju.

\section{INTRODUÇÃO}

A virada do século XXI acompanhou uma série de riscos e instabilidades que afetaram todas as atividades econômicas em nível global, incluindo-se o turismo. Tais instabilidades ocorreram e ocorrem em vários âmbitos, a exemplo dos conflitos sociais; conflitos armados; instabilidades políticas; crises econômicas; desastres e catástrofes naturais; ataques terroristas; riscos culturais, doenças e epidemias/pandemias, entre outros. Os ataques terroristas em Nova Iorque (2001), Paris (2015) e Barcelona (2017); a pandemia de H1N1 (2009), a "Primavera Árabe" (2010) e os conflitos sociais na Turquia (2016) são exemplos de eventos que geraram instabilidades econômicas e sociais que afetaram as viagens turísticas (Pieri \& Panosso Netto, 2015; UNWTO, 2017).

É certo que todos os deslocamentos envolvem riscos percebidos e/ou reais, sendo o primeiro relacionado aos eventos que ocorrem pré-viagem, durante ou pós-viagem e o segundo em tempo real. No entanto, a chegada do novo século também acarretou transformações no comportamento dos turistas, uma vez que o consumo de experiências associado ao reequilíbrio, à consciência e à preocupação ambiental, à valorização da segurança do destino e ao uso das tecnologias de informação e comunicação (mobile-first, cachless payments, traduções em tempo real, $Q R$ Code nos atrativos e serviços, etc.) são algumas das tendências que marcam o turismo e o consumidor turístico na atualidade (Trigo \& Mazaro, 2012).

Neste cenário de riscos e instabilidades, mais recentemente, o vírus SARS-CoV-2, também conhecido como COVID-19, tal qual outros vírus que geraram pandemias anteriores, a exemplo da gripe espanhola de 1918-19 que se estima ter ceifado cerca de $1 \%$ a 3\% da população mundial (Filho, 2020), trouxe à tona uma série de aspectos que merecem atenção nos âmbitos sociais, econômicos, culturais e comportamentais, uma vez que apresenta alto índice de transmissibilidade e mortalidade. Evidentemente, a disseminação rápida da COVID-19 - tendo no turismo internacional um vetor de suma importância para a propagação mundial da doença - gerou diversos impactos diretos na prática turística que se somam aos fatores de mudanças comportamentais emergidos no começo do século, ocasionando novos e profundos desafios para o planejamento turístico local no que tange à reformulação da prestação de serviços.

Em fevereiro de 2020, a Organização Mundial da Saúde (OMS) declarou estado de emergência de saúde pública de interesse internacional em relação ao vírus, o que ocasionou a situação de alerta global, a fim de se entender e, sobretudo, definir estratégias e alternativas que minimizassem o processo de disseminação viral que se alastrava por todo o mundo. Em 11 de março de 2020, o diretor-geral da OMS declarou que o SARS-CoV-2, devido à sua disseminação geográfica rápida, tratava-se de uma pandemia (UNASUS, 2020), fato que desencadeou diferentes medidas sanitárias, inclusive com alteração da dinâmica dos deslocamentos domésticos e internacionais.

A partir das recomendações da OMS, um novo cenário turístico mundial começou a ser desenhado. Nos primeiros meses da pandemia, a Organização Mundial do Turismo (OMT) apontou que 83\% dos destinos na Europa fecharam por completo as fronteiras [aérea e terrestre] ao turismo internacional. Nas Américas, o percentual foi de 80\%, na Ásia e Pacífico de 70\%, no Oriente Médio cerca de 62\% e no continente africano foi de 57\% (UNWTO, 2020a). Além disso, nesse mesmo período, os principais destinos mundiais receptores de turistas internacionais foram os mais afetados na primeira onda da COVID-19 e, após as flexibilizações impostas pelos governos no verão do hemisfério norte do mesmo ano, estes voltaram a ser os mais afetados na segunda onda, a exemplo da França e da Espanha. 
No Brasil, mesmo após a OMS decretar o estado pandêmico, acompanhamos certa debilidade no processo de tomada de decisão. O governo decretou medidas restritivas em 20 de março e no dia anterior publicou a Portaria da Casa Civil no .126 , de 19 de março de 2020, que dispõe sobre a restrição excepcional e temporária de entrada no país de estrangeiros oriundos da China, dos países membros da União Europeia, Islândia, Noruega, Suíça, Reino Unido da Grã-Bretanha, Irlanda do Norte, Austrália, Japão, Malásia e Coréia (Brasil, 2020a).

As Unidades da Federação passaram a estabelecer medidas restritivas e decretos sanitários de acordo com a magnitude de cada caso. O Distrito Federal, no mesmo dia que a OMS anunciou o estado pandêmico, suspendeu as aulas em todos os níveis e os eventos com público superior a 100 pessoas por 5 dias (Massalli, 2020). Já São Paulo, um dos principais portões de entrada de turistas do país, começou a adotar as primeiras restrições no dia 13 de março de 2020. Ambas as localidades se anteciparam às medidas que seriam adotadas posteriormente pelo governo federal.

No caso do Estado de Sergipe, do qual a cidade de Aracaju (nosso objeto de estudo) é a capital, o primeiro decreto - Decreto no. 40560 - foi aprovado em 16 de março e publicado no dia 17 de março de 2020 no Diário Oficial do Estado (DOE) (Sergipe, 2020). Essa normativa dispõe sobre a decretação de situação de emergência na saúde pública do Estado de Sergipe, em razão da disseminação do vírus SARS-CoV-2 e regulamenta as medidas para enfrentamento da crise de saúde pública de importância internacional. Tais medidas visaram à suspensão de eventos com mais de 50 pessoas; atividades coletivas em teatros e cinemas; visitação aos presídios e centros de detenção; e, atividades educacionais em todos os níveis por 15 dias.

Essas foram ações iniciais adotadas por algumas das Unidades da Federação, mas evidenciamos que em todo o território nacional até os dias atuais foram sancionadas apenas medidas específicas, devido à ausência de um controle efetivo da disseminação e mortalidade da doença, mesmo com um plano nacional de imunização contra o vírus SARS-Cov-2. Embora algumas deliberações sejam mais restritivas e outras baseadas em flexibilizações de alguns setores, medidas mais firmes no combate à pandemia se fazem extremamente necessárias para tentar reduzir o número de casos e vítimas.

A evolução da propagação do vírus e da crise sanitária gerou uma série de incertezas que afetaram profundamente o setor de turismo devido às medidas restritivas, bem como gerou impacto psicossocial ocasionado pelo isolamento e pelas demandas por cuidados sanitários, como o uso de máscaras. No entanto, esse cenário "oferece uma oportunidade singular para a reflexão e reorganização com a finalidade de crescer novamente e crescer de uma forma que seja melhor para o planeta e para as pessoas” (OMT, 2020, p. 6, tradução nossa). Com isso, este artigo parte da hipótese de que inúmeras transformações foram produzidas nos serviços turísticos a partir da pandemia da COVID- 19 que se iniciou no ano de 2020, iluminando novos e complexos desafios para o planejamento turístico.

Neste sentido, o estudo tem como objetivo analisar as implicações no turismo, especificamente, nos serviços turísticos da cidade de Aracaju/SE, a partir das medidas restritivas instituídas com a pandemia. Torna-se relevante salientar que esta investigação com o recorte espacial no contexto aracajuano faz parte dos estudos do Grupo de Pesquisa "Turismo em Tempos de Pandemia: Uma Abordagem Multi e TransEscalar" ${ }^{\text {[1] }}$ que tem como objetivo identificar e analisar os impactos da pandemia no Brasil e Argentina, na América do Sul; Portugal, no continente europeu e Moçambique, na África.

\section{Procedimentos Metodológicos}

A pesquisa é de natureza exploratória, com uma abordagem quanti-qualitativa. Como procedimento metodológico, primeiramente, foi realizado um levantamento bibliográfico para subsidiar e fundamentar a análise dos resultados. Posteriormente, foi executada uma pesquisa documental para identificar e analisar os decretos e portarias dos governos federal e estadual, bem como da prefeitura municipal de Aracaju, a fim de acompanhar as ações e medidas restritivas adotadas a partir da declaração da pandemia. Para análise da 
variação de empregabilidade nas atividades características do turismo (ACT's) foram utilizados dados do Cadastro Geral de Empregados e Desempregados (Caged), do Ministério da Economia.

Ademais, foram realizadas entrevistas com representantes do órgão municipal de turismo e do sindicato de guias de turismo e aplicados 317 formulários com residentes em Aracaju através da ferramenta Google Forms, no período de março a maio de 2021, visando captar os impactos gerados, estratégias em curso e tendências do turismo.

\section{Breve cenário do turismo de Aracaju pré-COVID}

A cidade de Aracaju, com uma área de $181 \mathrm{~km}^{2}$ e uma estimativa de 664.908 habitantes (IBGE, 2020a), configura-se como o principal centro urbano do estado de Sergipe, destacando-se por suas funções políticoadministrativas, comerciais, industriais e de prestação de serviços (Santos, 2017).

Entendendo a lógica do capital e da competitividade a partir da produção de centralidades, a rede hoteleira, as agências de viagens, assim como os principais estabelecimentos de alimentos e bebidas (A\&B) e demais equipamentos de apoio ao turista, se fixaram nas capitais visando a aproveitar as vantagens econômicas através do incremento de novos fluxos de pessoas dos últimos anos pré-pandemia (Silva \& Santos, 2015). Em Aracaju, essa realidade não difere, tendo em vista que se trata da cidade sergipana com maior infraestrutura turística, o que faz com que muitas das ações vinculadas às políticas públicas de turismo que são desenvolvidas em âmbito estadual, sejam destinadas a esta cidade em detrimento de outras que também compõem o mapa do turismo brasileiro. Não obstante, Silva e Santos (2015, p. 194), ao discutirem o turismo em Aracaju, afirmam que, de fato, essa cidade "acompanhou as oportunidades e incentivos do Governo Federal ao setor turístico, adequando e reestruturando seus espaços urbanos através de políticas de desenvolvimento do turismo em Sergipe".

A cidade de Aracaju integra o Polo Costa dos Coqueirais, considerado prioritário pelo governo estadual, uma vez que, além da capital, também estão inseridos os municípios localizados na faixa litorânea do estado. No entanto, apesar do polo integrar 13 (treze) municípios, estudos de consultorias contratadas pelo próprio Estado (Sergipe, 2013), bem como Santos (2017), comprovam que há uma centralidade em Aracaju, se tornando imprescindíveis ações mais eficazes no estabelecimento de novos modelos de desenvolvimento do turismo que visem promover alternativas para o uso racional do espaço e dos recursos turísticos do polo, assim como elaborar novos produtos turísticos competitivos.

De acordo com as indicações presentes no Plano de Desenvolvimento Integrado do Turismo Sustentável do Polo Costa dos Coqueirais - PDITS (Sergipe, 2013), é importante estabelecer metas para aumentar a atração de turistas a partir dos produtos ou atrativos turísticos comercializados em todos os municípios do Polo, a fim de ocasionar uma ruptura na concentração dos serviços na cidade de Aracaju.

No entanto, vale ressaltar que a partir da Categorização dos Municípios instituída pelo Ministério do Turismo por meio da Portaria $\mathrm{n}^{\circ}$. 144, de 27 de agosto de 2015, dentro da realidade sergipana, Aracaju é o único município presente na Categoria $\mathrm{A}$, o que faz com que ele receba uma atenção especial no que tange aos investimentos turísticos, em detrimento dos demais. De acordo com o MTur (Brasil, 2016), essa categorização tem como objetivo auxiliar no processo de tomada de decisões estratégicas da gestão pública, elaboração e implementação de políticas específicas para cada categoria de municípios.

Apesar da preponderância de Aracaju no contexto do turismo sergipano, percebe-se a premência de quebra desse status quo, uma vez que as velhas práticas de associação da atividade turística somente ao segmento de sol e praia não tem permitido a diversificação da oferta turística local e, consequentemente, não contribui para o aumento do tempo de permanência do turista na referida cidade. De acordo com os dados fornecidos pela Secretaria Municipal da Fazenda (SEMFAZ), a receita municipal do Turismo (ISS do setor) ${ }^{[2]}$ no ano de 2019 - antes da pandemia - totalizou R \$5.071.872,11, o que corresponde a apenas 1,76\% do total da receita 
municipal dos serviços. Porém, torna-se importante salientar que o serviço de hotelaria foi responsável por uma arrecadação de R \$ 4.251.885,45, ou seja, 83,8\% entre as atividades características do turismo.

Assim sendo, percebe-se que o cenário do turismo de Aracaju antes da pandemia da COVID-19 já merecia uma atenção especial, tendo em vista as mudanças no processo de segmentação e espacialização do consumo turístico. A partir da pandemia, as discussões e preocupações sobre como retomar as atividades do setor de serviços do turismo e ampliação das viagens se tornam urgentes, uma vez que o fechamento das atividades turísticas e a diminuição dos deslocamentos incidiram principalmente nas maiores perdas do volume de empregos diretos e indiretos do período (IBGE, 2020b).

Destarte, Aracaju está localizada entre dois destinos consolidados da região Nordeste do Brasil, Salvador e Maceió, o que carece de definição de estratégias e ações que possam contribuir no posicionamento competitivo da cidade no mercado turístico brasileiro, principalmente no momento de retomada das atividades.

Nesse sentido, diante do impacto no setor de turismo que a pandemia da COVID-19 anunciou, ao analisar o destino Aracaju, faz-se mister apontar suas principais características e debilidades em termos de planejamento turístico anterior a este grande evento de proporções globais. Para que a análise póspandemia seja realizada de forma situada na realidade local, os fatores históricos são relevantes, já que podem influir significativamente no processo tornando a atividade mais vulnerável frente a outros destinos concorrentes. Assim, consideramos que, embora os impactos no turismo sejam evidentes e inquestionáveis, estes se realizarão de forma distinta entre países, regiões e lugares, o que demanda uma análise multiescalar (Cruz, 2020a).

Com isso, objetiva-se que as questões que entravam o turismo de Aracaju, ainda não superadas, possam ser encaradas com os novos obstáculos emergidos em um contexto generalizado de crise no setor, provocado pela paralisia e redução das viagens durante o período pandêmico que afetou todos os destinos turísticos. Isto posto, os novos desafios de Aracaju se colocam com características peculiares dado o cenário turístico anterior que se apresenta problemático e que devem ser evidenciadas por meio de estudos na relação totalidade-lugar.

\section{AnÁlise dos Serviços turísticos de Aracaju no momento PandÊMico}

Em decorrência da pandemia é redundante afirmar que há uma crise no turismo mundial a partir do cancelamento dos voos, fechamento de fronteiras, estabelecimentos, equipamentos e atrativos turísticos. De acordo com a OMT (2020), nos primeiros 10 meses do ano de 2020, as viagens internacionais apresentaram uma queda de $72 \%$, uma vez que os destinos receberam 900 milhões a menos de turistas comparando com o mesmo período do ano anterior. A Ásia e o Pacífico registraram uma redução de 82\%; Oriente Médio de 73\%; África de 69\%; Europa e América de 68\%. Isso resultou numa perda de 935 milhões de dólares provenientes do turismo internacional.

Já para o início do ano de 2021, o barômetro da OMT aponta que durante os cinco primeiros meses, os destinos apresentaram uma redução de 147 milhões em chegadas internacionais, comparado ao mesmo período de 2020. Contudo, ao analisarmos em relação ao ano de 2019, a redução é de 460 milhões.

No Brasil, apesar do governo federal não ter adotado medidas para fechamento de fronteiras e de proibição de chegada de voos internacionais, as próprias empresas aéreas foram responsáveis pela redução dos voos. De acordo com o relatório de impacto da pandemia da COVID-19 nos setores de turismo e cultura no Brasil (Brasil, 2020b, p. 20-21),

os voos internacionais regulares, que os aeroportos brasileiros recebem, foram mais impactados que os domésticos, apresentando queda de $61 \%$ nos desembarques, de 54\% na quantidade de voos e de 58\% na oferta de assentos comercializados, de janeiro a julho 2020 comparado ao mesmo período do ano anterior. Além disso, a taxa de ocupação média nas aeronaves chegou a 20,5\% em maio de 2020 . 
A região Nordeste apresentou uma queda de 51,8\%, o que refletiu nos dados de desembarque no aeroporto de Aracaju. De acordo com a entrevista realizada com o responsável pela Secretaria Municipal de Indústria, Comércio e Turismo (SEMICT), "para o monitoramento do fluxo turístico de Aracaju, a SEMICT utiliza como dados a movimentação de passageiros no Aeroporto Santa Maria”. Assim sendo, a partir dos dados da Agência Nacional de Aviação Civil (ANAC) e da AENABRASIL (administradora do Aeroporto Santa Maria), comparando-se os anos de 2019 e 2020 observa-se uma redução de 50,29\% no volume total de passageiros, principalmente entre os meses de abril e agosto de 2020, período que corresponde a primeira onda de contaminações e ao ápice da média de mortes diárias pela COVID-19 (Gráfico 1).

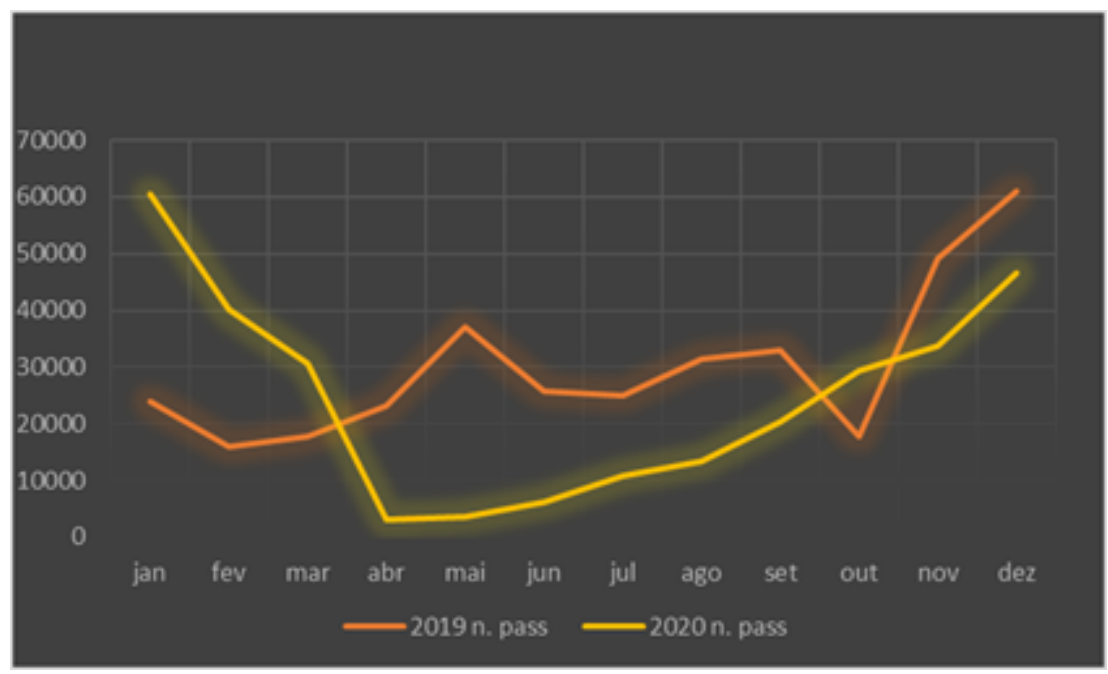

GRÁFICO 1

Aeroporto Santa Maria - Aracaju: Variação de movimentação de passageiros - 2019/2020 Brasil, Agência Nacional de Aviação Civil, 2021a.

A redução nos aeroportos, assim como os fluxos rodoviários de ônibus de passageiros, que também sofreu uma redução de $77,1 \%$, passando de 336.524 passageiros, em 2019, para apenas 77.399 , em 2020 (Brasil, 2021b), deve-se invariavelmente às medidas restritivas impostas pelos governos estaduais e ao receio de contaminação durante o deslocamento no sistema de transporte.

É importante ressaltar que os dois primeiros meses do ano de 2020 apresentaram uma variação baixa, tendo em vista que as medidas restritivas no país começaram a ser adotadas no mês de março. Por outro lado, o mês de abril apresentou a maior queda comparativa nas atividades produtivas, impactando diretamente o setor de turismo de Aracaju. As medidas foram acentuadas a partir do Decreto n ${ }^{\circ} .40 .588$ de 27 de abril de 2020, que aplicou o Distanciamento Social Seletivo (DSS), fechando outros setores de atividades comerciais e de serviços, como a proibição de entrada de novos hóspedes nos meios de hospedagem; restrição temporária de funcionamento de bares, restaurantes e lanchonetes que passaram a funcionar somente nos sistemas delivery e/ou take away. Com isso, a arrecadação municipal oriunda do setor de turismo no ano de 2020 teve uma queda de 51,57\% comparada ao ano de 2019 (Aracaju, 2021).

Se analisarmos por setor de atividade, verifica-se que a arrecadação municipal teve uma variação de $-48,42 \%$, sendo que as maiores perdas foram relacionadas ao cancelamento dos serviços de shows e eventos com $-68,20 \%$ (Tabela 1 ). 
TABELA 1

Aracaju - Variação da arrecadação por setor de atividade 2019 - 2020

\begin{tabular}{|c|c|c|c|c|}
\hline \multirow[b]{2}{*}{ Setor de Atividade } & \multicolumn{3}{|c|}{ Arrecadação por setor } & \multirow[b]{2}{*}{$\begin{array}{l}\text { Variação } \\
\%\end{array}$} \\
\hline & 2019 & 2020 & Variação & \\
\hline $\begin{array}{l}\text { Serviços de } \\
\text { Hotelaria }\end{array}$ & $4.251 .885,45$ & $2.331 .736,60$ & $-1.920 .148,85$ & $-45,16 \%$ \\
\hline $\begin{array}{l}\text { Serviços de Agência } \\
\text { de Turismo }\end{array}$ & $471.713,15$ & $162.058,55$ & $-309.654,60$ & $-65,64 \%$ \\
\hline $\begin{array}{l}\text { Serviços Showse } \\
\text { Eventos } \\
\text { Serviços de }\end{array}$ & $202.703,01$ & $64.450,14$ & $-138.252,87$ & $-68,20 \%$ \\
\hline $\begin{array}{l}\text { Produção de Shows } \\
\text { e Espetáculos } \\
\text { Serviços de }\end{array}$ & $101.362,38$ & $36.742,51$ & $-64.619,87$ & $-63,75 \%$ \\
\hline $\begin{array}{l}\text { Exposição, Feiras, } \\
\text { Congressos }\end{array}$ & $44.208,12$ & $21.014,91$ & $-23.193,21$ & $-52,46 \%$ \\
\hline Total & $5.071 .872,11$ & $2.616 .002,71$ & $-2.455 .869,40$ & $-48,42 \%$ \\
\hline
\end{tabular}

Aracaju, Secretaria Municipal da Fazenda, 2021.

No município de Aracaju, o segmento de serviços foi aquele que apresentou o pior saldo no acumulado do ano de 2020, com -2.332 postos de trabalho (Gráfico 2). Neste aspecto, é possível observar que, apesar da tendência de saldos negativos entre os meses de março e setembro, a partir de outubro o saldo apresentou relativa melhora, decorrente da retomada de algumas atividades econômicas e da flexibilização das medidas de isolamento social no estado de Sergipe.

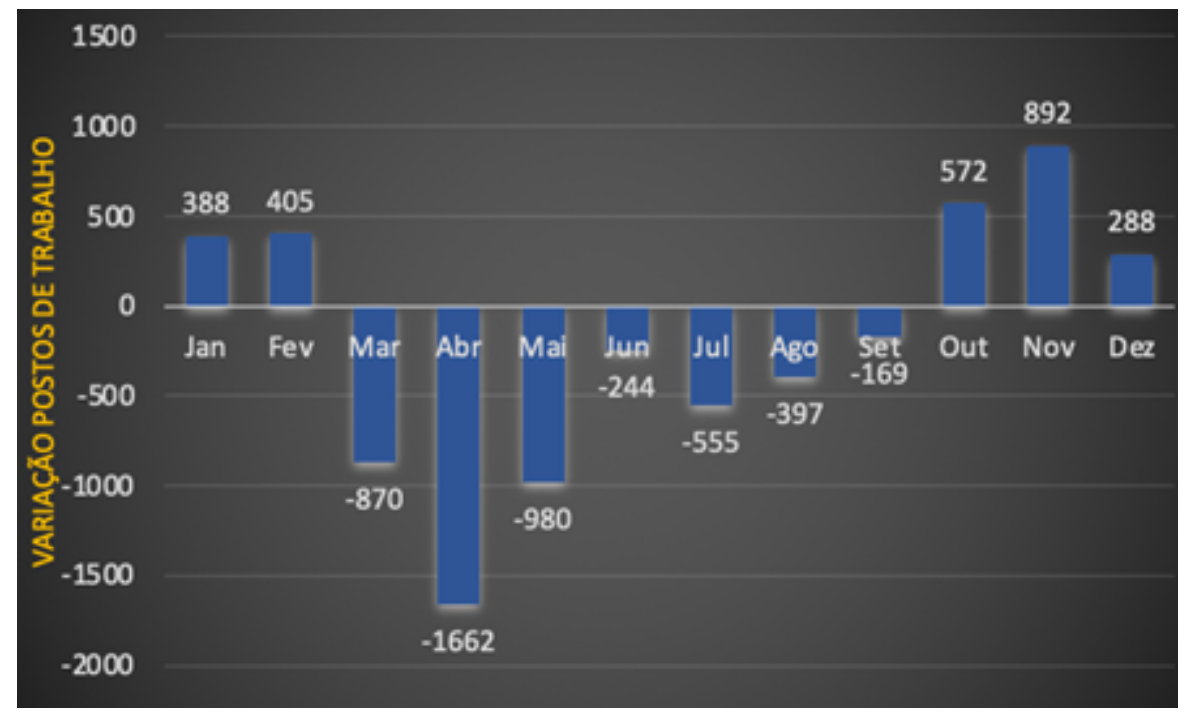

GRÁFICO 2

Aracaju - Variação mensal de emprego formal no setor de Serviços, 2020 Brasil, Ministério da Economia, Caged, 2020c.

Apesar de não termos acesso aos dados da contribuição do setor de $A \& B$ na arrecadação municipal por tipologia de atividade, a partir das análises dos dados do Caged, observa-se que este setor e os meios de hospedagem foram os mais afetados no que diz respeito às variáveis admissão e desligamento, comparando-se os anos de 2019 (pré-pandemia) e 2020. Enquanto no setor de A\&B, o balanço entre admissóes e demissões no período conta com um saldo negativo de 727 postos de trabalho, na hotelaria o saldo foi de -322 empregos formais (Gráfico 3). 


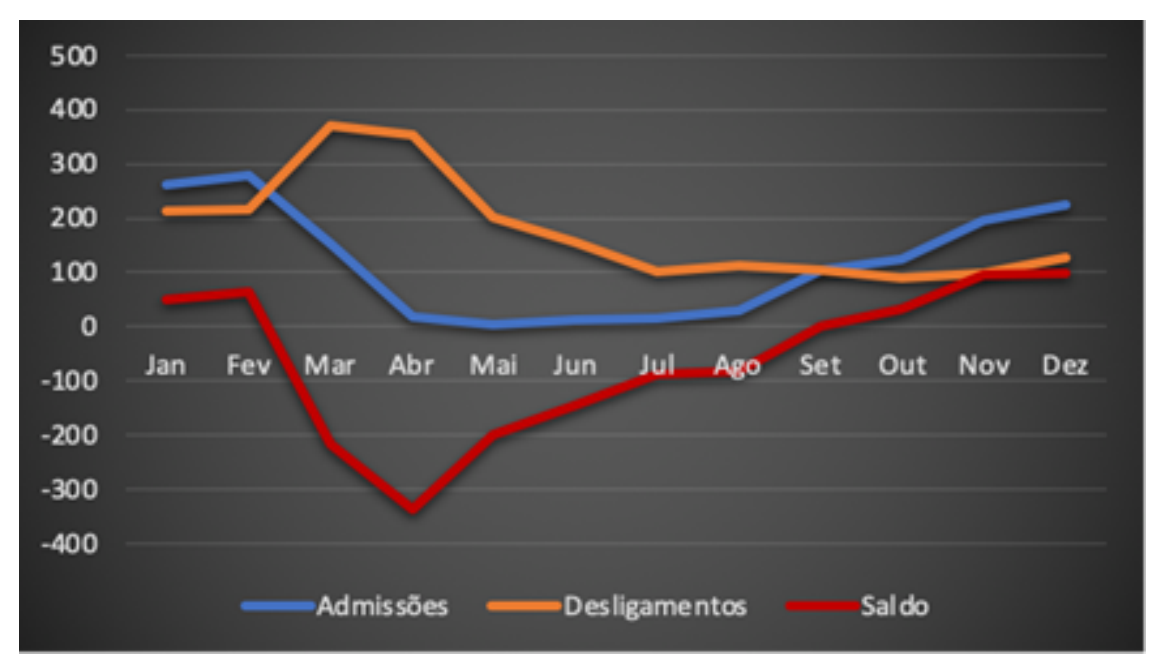

GRÁFICO 3

Aracaju - Variação mensal de emprego formal no setor de Restaurantes e outros estabelecimentos de serviços de alimentação e bebidas, 2020 Brasil, Ministério da Economia, Caged, 2020c

De acordo com a Associação Brasileira de Bares e Restaurantes (Abrasel/SE), a partir de sua pesquisa realizada em março de 2021 sobre o impacto das medidas restritivas nos bares, restaurantes e similares,

As restrições impostas trazem um impacto enorme na viabilidade do segmento de bares, restaurantes e similares. Indicando que $61 \%$ dos empresários estão buscando manter em funcionamento, mas não possuem condições. Sendo que $6,8 \%$ já fecharam ou já decidiram por fechar, e 10,2\% não possuem condições sequer de arcar com os custos do fechamento (Abrasel, 2021, s/p).

As pressões por abertura dos diversos setores da economia aracajuana ocorreram em meio aos processos de restrição da mobilidade urbana, que definiu horários de funcionamento com toque de recolher a partir das 22 horas, além de diversas suspensões e fechamentos parciais das áreas comerciais, estabelecimentos religiosos e outros tipos de atividades que gerassem aglomerações (Decreto $\mathrm{n}^{\circ} .6 .111$, de 16 de abril de 2020, e subsequentes). Mesmo sem a adoção de lockdown, entre março de 2020 e fevereiro de 2021, o faturamento do setor de A\&B apresentou os piores índices. Segundo a pesquisa da Abrasel/SE, 81,4\% dos empresários do setor não conseguiram manter folha de pagamento em dia, $86,4 \%$, não cumpriram pagamento de tributos federais e estaduais, enquanto $79,7 \%$ não conseguiram arcar com os tributos municipais (Abrasel, 2021).

Por outro lado, as empresas de organização de eventos, agências de viagens e de locação de veículos, que também são importantes empregadores na cidade de Aracaju, apresentaram perdas de postos de empregos na ordem de 414,0\%, 133,3\% e 66,7\% respectivamente (Brasil, 2020c). Dentre estas, as empresas de organização de eventos foram as que apresentaram as maiores perdas, tendo em vista que as medidas de isolamento social e as proibições de qualquer tipo de evento impossibilitaram a retomada do setor. As agências de viagens e de locação de veículos apresentaram percentuais menores, uma vez que as atividades atreladas a estes setores não foram cessadas por completo, mesmo considerando o momento adverso. Tal fato pode ser comprovado a partir da análise das respostas ao formulário aplicado ${ }^{[3]}$ com residentes de Aracaju que abordou sobre a realização de viagens no período de pandemia, no qual 43,22\% dos respondentes informaram que realizaram ao menos uma viagem a lazer no ano 2020, sendo os destinos mais procurados aqueles localizados no próprio estado ou nos estados mais próximos, como Bahia e Alagoas.

Outro setor de atividade que também foi atingido durante este período pandêmico foi o de guias de turismo. Segundo a entrevista realizada com a representante do Sindicato dos Guias de Turismo ${ }^{[4]}$ (SINGTUR/SE), o próprio sindicato se mobilizou para a distribuição de cestas básicas entre os guias de Aracaju e Nossa Senhora do Socorro, município que integra a Região da Grande Aracaju, como ação de 
amparo ao trabalhador neste momento de crise. Ademais, a entrevistada ressaltou que não houve uma política estabelecida pelos governos municipais, uma vez que somente surgiram propostas de adesão a financiamentos através de linha de crédito gerada pelo Banco do Estado de Sergipe. Fato que nada auxilia o profissional ao se submeter às exigências e restrições da rede bancária, contribuindo para aumentar a dívida pessoal.

Não obstante, além das atividades formais do turismo, os trabalhadores informais que correspondem aos vendedores ambulantes nas praias, praças e demais atrativos, bem como artesãos, garçons e cozinheiros dos quiosques de praia, fornecedores e vendedores de crustáceos (caranguejo), guardadores de carro em vias públicas, entre outros, ficaram sem trabalho nesse período, ampliando a situação de vulnerabilidade social e econômica, uma vez que nem todos tiveram acesso às parcelas do Auxílio Emergencial de $\mathrm{R} \$ 600,00$ do Governo Federal, que não supre as despesas para sustentar a família (Brasil, 2020d).

Assim, torna-se urgente a elaboração de propostas criativas e novos protocolos de reativação das atividades do setor, porém acreditamos que qualquer ação neste sentido está sob influência de fatores externos aos stakeholders dos destinos, devendo-se atentar as prerrogativas como a erradicação da COVID-19, com a administração da vacina, conforme as orientações da OMS.

\section{NOVAS FORMAS DE TURISMO PÓS-COVID 19?}

Os últimos acontecimentos mundiais instaurados pela pandemia da COVID-19 impuseram novas condições à práxis social, redefinindo as relações e, por conseguinte, o cotidiano enquanto reprodução da vida. A amálgama neoliberal se acentua frente ao isolamento social - imposto pela demanda de contenção da disseminação generalizada e desenfreada do vírus SARS-Cov-2-, levando ao aprofundamento da tônica indivíduo-individualismo-individualização e ao aumento do tempo do trabalho produtivo, que invade o espaço da casa e a vida privada com uma parcela de trabalhadores circunscritos e restritos ao ambiente doméstico (Carlos, 2020).

Neste período inaugurado, de acordo com Carlos (2020, p. 12), o tempo da valorização dominou não somente as relações sociais, como também ultrapassou o limiar da porta da moradia, de modo que "[...] o espaço doméstico é, hoje, cada vez mais o ateliê onde o habitante vai transformando todos os momentos da vida privada em 'trabalho em ação'”. Nesse sentido, a baixa socialização produzida pelo distanciamento social e quarentena conduz ao desenvolvimento generalizado de doenças da psique humana, abalando a saúde emocional e mental (Bianchi, 2020).

Nesse contexto, o turismo, para alguns, mais atentos e inflexíveis com as medidas de segurança sanitária, tornou-se um "hábito" de férias impraticável; enquanto, para outros, pôde se tornar um refúgio frente ao caos colocado pela pandemia em diversos âmbitos da sociedade. Ao analisarmos os dados da pesquisa realizada com os residentes de Aracaju, dentre os respondentes 56,78\% informaram não ter realizado nenhum tipo de viagem durante a pandemia. É importante ressaltar que $45,83 \%$ mencionaram a falta de confiança na maneira como o poder público, federal, estadual e municipal, enfrenta a pandemia como fator preponderante em sua decisão de não realizar viagens.

Por outro lado, o isolamento exacerbado produtor do cotidiano tedioso e pouco movimentado pela impossibilidade de realização de atividades que antes eram promovidas fora da residência, fazem com que o turismo possa se configurar como uma possível e imediata solução para a tensão concentrada no lar pela imposição do tempo produtivo sob a vida. Assim, as problemáticas trazidas pela pandemia levariam a um desejo reprimido de viajar em alguns indivíduos como momento de descanso, "[...] uma válvula de escape para a ansiedade e as incertezas trazidas pelo novo coronavírus, sendo, portanto, absolutamente compreensível" (Cruz, 2020b, s/p), revelando o fator de reparação social/pessoal que o turismo possui em si ao promover deslocamento temporário da residência cotidiana.

Muito tem se falado nos portais de notícias do mercado turístico, como Panrotas e Viagem\&Turismo sobre as novas tendências para as práticas turísticas, como preços mais baixos; demanda por parte dos turistas 
por mais transparência nas transações; preferência por destinos próximos e de contato com a natureza; preferência por equipamentos e atrativos turísticos com medidas sanitárias, entre outras. Além disso, as plataformas frisam as mudanças no comportamento do turista em potencial, o que demandará criatividade dos empreendimentos do setor frente ao novo ambiente de insegurança e instabilidade (Andrade, 2020). Tais constatações estão presentes na pesquisa realizada com os residentes de Aracaju, na qual 56,93\% dos inquiridos informaram que as medidas de segurança e biossegurança influenciaram e foram determinantes no momento de decisão por viajar durante o período pandêmico, assim como destaca-se a tendência por viagens ao interior em áreas naturais $(32,12 \%)$ e praias em área natural $(53,28 \%)$ em contraposição às praias localizadas em áreas urbanas (29,20\%).

De mesmo modo, é levantada a possibilidade de rápida retomada ${ }^{[5]}$ (tornando o setor atrativo para investimentos internacionais), inflado pelo próprio Ministério do Turismo do Brasil (MTur) ${ }^{[6]}$ que é contrário às medidas de isolamento em nome do crescimento econômico, seguindo a tônica preconizada pelo chefe do Executivo e seus ministros especializados na gestão da pandemia fundada na necropolítica ${ }^{[7]}$.

Nesse sentido, ao indagarmos sobre as novas formas de turismo em Aracaju, primeiramente se faz pertinente avaliar a possibilidade de uma mudança efetivamente sistêmica da prática turística, isto é, uma grande ruptura no setor que sinalize novos rumos para a prática. $\mathrm{Na}$ escala mundial, de acordo com Bianchi (2020), as formas mais sustentáveis de turismo continuarão sendo um paradigma no contexto da expansão contínua do capitalismo, de modo que, embora as estratégias mudem para que o mercado se adeque às novas demandas de saúde pública ensejada pelos turistas, as metas e, sobretudo, a tônica do crescimento neoliberal - acumular, produzir e reproduzir - tendem a permanecer.

O Brasil apresenta sinais e tendências que nos ajudam a levantar hipóteses sobre o futuro do turismo no país e, especificamente, em Aracaju. Segundo a análise realizada por Cruz (2020c, p. 12) “[...] os fluxos intrarregionais de turistas apresentam uma tendência de crescimento mais rápido em relação a viagens de longa distância, as quais talvez somente voltem a crescer após a ocorrência de uma vacinação em massa”. $\mathrm{O}$ mercado turístico também está atento a uma possível tendência de fortalecimento do turismo doméstico e regional, considerando-se as pesquisas de demanda realizadas que sinalizam para o receio do turista em relação ao contágio durante a viagem.

Desta forma, a pandemia da COVID-19 tem moldado o comportamento do turista brasileiro no sentido de preferências por viagens curtas com hospedagem em ambientes controlados, como é o caso dos aluguéis por temporada, levando ao crescimento especificamente desse setor de hospedagem, tanto pelo custo mais baixo, quanto pela possibilidade maior de isolamento social (Favaro, 2021). Com a ausência de uma gestão pública efetiva para minimizar a disseminação do coronavírus no Brasil, a tendência é que o turismo retome de forma lenta seu patamar pré-pandemia, com destaque para dificuldades no que tange à atração de turistas estrangeiros, de modo que as regióes e lugares que recebem massas de turistas advindos de destinos distantes geograficamente passarão a receber outro perfil de turistas, de locais mais próximos.

Diante do exposto, no caso da cidade de Aracaju, novas formas de turismo pós-COVID-19 devem partir de um diagnóstico que seja pautado nos impactos que a pandemia trouxera especificamente para o destino turístico, evidenciando as perdas na arrecadação de impostos, empregos diretos e indiretos e fechamento de estabelecimentos (dados demonstrados por este estudo), a fim de traçar um plano de açóes coerente com o cenário do mercado turístico local e regional. Assim, será possível superar a atual crise posta pela pandemia mediante a definição de estratégias e ações que possam contribuir no posicionamento competitivo da cidade no mercado turístico brasileiro, principalmente no momento de retomada das atividades, levando-se em consideração as tendências que surgirão por parte da demanda turística, conforme apontamos anteriormente.

Para tanto, faz-se mister que os gestores turísticos locais não percam de vista os problemas que se apresentavam anteriormente à pandemia, como a centralidade e concentração turística na cidade de Aracaju. Ademais, a urgência da diversificação da oferta tendo por objetivo a formatação de novos produtos turísticos que sejam capazes de atrair a demanda turística reprimida que, conforme apontamos, buscará viagens curtas 
em ambientes controlados, atraindo a preferência pelo turismo regional e destinos menores, o que pode ser positivo para atrair turistas à cidade de Aracaju dadas as suas características. Em suma, consagra-se o momento de rever criticamente as posições que Aracaju tem assumido no mercado turístico nacional, a fim de traçar um novo e moderno modelo de desenvolvimento visando o incremento de sua competitividade enquanto destino turístico no contexto pós-pandemia.

Além disso, Santos e Campos (2021) asseguram que, para retomada, os destinos devem investir na adoção de novas normas de biossegurança, novas formas de regulação e gestão inteligente dos espaços e maior transparência do marketing nas mais diversas mídias digitais através da criação campanhas baseadas na adoção de selos ou indicadores de boas práticas que atendam as recomendações sanitárias internacionais. Isso é ratificado por $56,93 \%$ dos respondentes, que afirmaram que as medidas sanitárias adotadas pelo destino são importantes para a definição da viagem. Somando-se a este dado, $80,44 \%$ do total acredita que a vacinação em massa da população é fator determinante para a retomada das viagens.

\section{CONSIDERAÇÕES}

As várias conjecturas sobre um período pós-pandêmico em que os turistas buscarão o turismo de natureza, sinalizando, caso a hipótese seja ratificada, uma clara tentativa de fuga às privaçóes do espaço urbano que impedem a realização da vida, contradições escancaradas pela/com a pandemia, enfocam somente a satisfação econômica de retroalimentação do mercado.

Nesse sentido, as especulações sobre uma explosão de demanda turística reprimida não são seguidas das reais necessidades que os destinos terão que apresentar a partir de novas configurações e novos significados. Tais configurações deverão suscitar a revalorização; usos amplos e diferenciados de espaços; 'exclusividades' que garantam a biossegurança coletiva, capacidade criativa e autenticidade relacional e inclusiva, que atendam aos diversos nichos sociais e, principalmente, que sejam ancoradas na transparência do marketing cada vez mais digital e nas multiplataformas capazes de promover a execução de práticas que sejam, ao mesmo tempo, democráticas, seguras e sustentáveis em médio e longo prazo.

Assim, o conjunto de atividades características do turismo em Aracaju, embora tenha percebido a sua maior crise tanto no campo empresarial, como na manutenção dos postos de trabalho de diversas categorias, os agentes do mercado turístico têm apostado que o setor de turismo se constituirá em um dos principais motores de crescimento econômico no pós-pandemia, discursos que possuem um papel de suma importância na atração de investidores.

Dessa maneira, ressaltamos que uma nova ordem de corresponsabilidades, redefinição dos padrões de recepção, assim como novos protocolos de biossegurança ajustados às normas globais associados à criatividade na exploração dos recursos (atrativos) com vistas à ampliação do tempo de permanência do turista no destino são as linhas gerais de um desenvolvimento turístico mais realista num cenário agora marcado por um novo paradigma - a crise pandêmica - e, consequentemente, em um novo turista.

Por fim, a pandemia no setor turístico evidenciou a importância do Estado (assim como na crise de 2008) em socorro às empresas turísticas, ratificando o desafio de neutralizar o controle por parte dos agentes dos mercados e do capital sobre a governança turística, sempre tensionado pela pressão empresarial. Porém, frente ao cenário delineado no setor turístico e a tendência de continuidade da lógica capitalista anterior com apenas novas nuances estratégicas para a atração dos turistas, torna-se importante ressaltar que urge uma mudança de paradigma, a fim de atender às novas exigências do consumidor turístico e que sejam capazes de promover o desenvolvimento amplo do turismo. 


\section{REFERÊNCIAS}

Abrasel. (2021). Pesquisa de Impacto das medidas restritivas nos bares, restaurantes e similares em Sergipe. 01 - 18 março. Disponível em: https://se.abrasel.com.br/ Acesso em 25 mai. 2021.

Andrade, A. L (2020). O que muda no comportamento do viajante pós-pandemia? Panrotas. Disponível em: https://www.panrotas.com.br/coronavirus/superando-o-coronavirus/2020/06/o-que-muda-no-comporta mento-do-viajante-pos-pandemia_174457.html. Acesso em 25 de julho de 2021.

Aracaju. (2021). Arrecadação de ISS por setor de atividade 2019 - 2020. Secretaria municipal da Fazenda, 2021.

Bevilaqua, J. (2020). Turismo regional é a tendência para o pós-pandemia. Pioneiro. Disponível em: https://gauchazh.clicrbs.com.br/pioneiro/economia/noticia/2020/08/turismo-regional-e-a-tendencia-pa ra-o-pos-pandemia-13043753.html Acesso em 26 de julho de 2021.

Bianchi, R. V. (2020). Covid-19 and the radical transformation of tourism? ATLAS Tourism and Leisure Review, v. $2,1-8$

Brasil. (2016). Ministério do Turismo. Cartilha da Categorização dos Municípios das Regiões Turísticas do Mapa do Turismo Brasileiro. Brasília: Ministério do Turismo. Disponível em: http://mapa.turismo.gov.br/mapa/downl oads/pdf/categorizacao/Cartilha_da_Categorizacao.pdf

Brasil, (2020a). Diário Oficial da União. Portaria no 126, de 19 de março de 2020. disponível em: https://www.in.gov .br/en/web/dou/-/portaria-n-126-de-19-de-marco-de-2020-248881688. Acesso em: 14 jun. 2021.

Brasil. (2020b). Ministério do Turismo. Relatório de impacto da pandemia de covid-19 nos setores de turismo e cultura no Brasil. Boletins de Estatísticas Turísticas. Disponível em: http://www.dadosefatos.turismo.gov.br/boletins. html Acesso em: 27 jun. 2021.

Brasil. (2020c). Ministério da Economia. Secretaria Especial de Previdência e Trabalho. Cadastro Geral de Empregados e Desempregados - Caged. Base de dados online. Disponível em: http://bi.mte.gov.br/bgcaged/caged.php. Acesso em: 3 jun. 2021.

Brasil. (2020d). Diário Oficial da União. Medida Provisória no 1.000, de 2 de setembro de 2020. Disponível em: https:/ /www.in.gov.br/en/web/dou/-/medida-provisoria-n-1.000-de-2-de-setembro-de-2020-275657334 Acesso em: 3 set. 20201.

Brasil. (2021a). Agência Nacional de Aviação Civil. Base de dados estatísticos do transporte aéreo. ANAC. Disponível em: https://www.anac.gov.br/assuntos/setor-regulado/empresas/envio-de-informacoes/microdados Acesso em: 3 mai. 2021.

Brasil. (2021b). Agência Nacional de Transportes Terrestres. Dados de início e fim de viagem do serviço regular coletados pelo Sistema de Monitoramento do Transporte Rodoviário Interestadual e Internacional Coletivo de Passageiros. Disponível em: https://dados.antt.gov.br/dataset/activity/monitriip-servico-regular-viagens Acesso em: 25 mai. 2021.

Carlos, A. F. A. (2020). A "Revolução" no Cotidiano invadido pela Pandemia. In: Carlos, A. F. A. COVID-19 e a Crise Urbana. (pp. 10-17). São Paulo: FFLCH/USP.

Cruz, R. C. A. (2020a). Impactos da pandemia no setor de turismo. Jornal da USP. São Paulo, 03 de julho de 2020. Disponível em: https://jornal.usp.br/artigos/impactos-da-pandemia-no-setor-de-turismo/. Acesso em 25 de julho de 2021.

Cruz, R. C. A. (2020b). O grito de independência de turistas pelo mundo e no Brasil. Le Monde Diplomatique Brasil. São Paulo, 14 de setembro de 2020. Disponível em: https://diplomatique.org.br/o-grito-de-independencia-deturistas-pelo-mundo-e-no-brasil/. Acesso em 25 de julho de 2021.

Cruz, R. C. A. (2020c). O evento da Covid-19 e seus impactos sobre o setor turismo: em busca de uma análise multi e trans-escalar. Revista Acadêmica Observatório de Inovação do Turismo, v. XIV, nº especial.

Favaro, C. (2021). Reservas no Airbnb já superam as do período anterior à pandemia. Disponível em: https://valor.g lobo.com/empresas/noticia/2021/08/26/reservas-no-airbnb-j-superam-perodo-pr-pandemia.ghtml Acesso em 28 de julho de 2021. 
Filho, R. P. C. (2020) A peste, a gripe espanhola e a covid19 - geografizando as pandemias pelo mundo. Élisée, Rev. Geo. UEG - Porangatu, v.9, n.1, jan./jun.

IBGE. (2020a). Cidades e Estados - Aracaju. Disponível em: https://www.ibge.gov.br/cidades-e-estados/se/aracaju.h tml? Acesso em: 27 jun. 2021.

IBGE. (2020b). Pesquisa Nacional por Amostra de Domicílios - PNAD COVID19. Disponível em: https://covid19.ib ge.gov.br/pnad-covid/ Acesso em: 10 jun. 2021.

Massalli, F. (2020) Coronavírus: governo do DF suspende aulas e eventos por cinco dias. Agência Brasil - Brasília. Disponível em: https://agenciabrasil.ebc.com.br/saude/noticia/2020-03/coronavirus-governo-do-df-suspende -aulas-e-eventos-por-cinco-dias Acesso em: 14 jun. 2021.

Organização Mundial do Turismo. (2020). Apoyo al Empleo y a La Economía a través de los Viajes y el Turismo Llamamiento a la acción para mitigar el impacto socioeconómico de la COVID-19 y acelerar la recuperación. Madrid, OMT. Disponível em: https://webunwto.s3.euwest-1.amazonaws.com/s3fs-public/2020-04/COVID19_Reco mmendations_ES.pdf. Acesso em 05 de maio de 2021.

Pieri, V. S. G., \& Panosso Netto, A. (2015). Turismo internacional: fuxos, destinos e integração regional. Boa Vista: Editora da UFRR.

Santos, C. A. J. (2017). El Turismo como Factor de Desarrollo: El caso de Sergipe. Barcelona, 2017. [Tese Doutorado em Geografia, Planificación Territorial y Gestión Ambiental, Universitat de Barcelona].

Santos, C. A. J., \& Campos, A. C. (2021). Reflexões sobre Residentes, Turistas e Espaços Púbicos pós- COVID - 19. In: Portuguez, A. P.; Trigo, L. G.G (Orgs.). Turismo e saúde global: pandemia, pandemônio e novos rumos para o setor no Brasil e no mundo. (pp. 140 - 168). Ituiutaba, Barlavento.

Sergipe. (2020). Diário Oficial do Estado - SE. Decreto no. 40560 de 16 de março de 2020. Disponível em: https://ww w.legisweb.com.br/legislacao/?id=390773. Acessado em 01 de julho de 2021.

Sergipe. (2013). Plano de Desenvolvimento Integrado do Turismo Sustentável (PDITS) do Polo Costa dos Coqueirais. Brasília, DF: Technum Consultoria.

Silva, J. A., \& Santos, C. A. J. (2015). Análise da competitividade do turismo no município de Aracaju. Revista de Turismo Contemporâneo, 3(2), 188-210. https://periodicos.ufrn.br/turismocontemporaneo/article/view/6887

Silva, R. C. \& Victorino, N. C. R (2020). ¿Biopolitica/Necropolitica? Covid-19: Un Posible Análisis De Situaciones Y Acciones de los Pueblos Tradicionales frente a La Pandemia en La Triple Frontera Del Amazonas/Alto Solimöes. In: Almeida, A. W. B. et. al. Pandemia e Território (pp. 315-336). São Luís, UEMA Edições.

Trigo, L. G. G., \& Mazaro, R. (2012). Movimentos Globais e Cenários em Turismo: uma realidade dinâmica, uma viagem ao futuro. Turismo em Análise, 23 (3), 486-508.

UNASUS, (2020). Organização Mundial de Saúde declara pandemia do novo Coronavirus. Disponível em: https://w ww.unasus.gov.br/noticia/organizacao-mundial-de-saude-declara-pandemia-de-coronavirus. Acesso em: 04 jun. 2021

World Tourism Organization (2017), 10YFP Sustainable Tourism Programme Annual Magazine 2016/2017 Advancing towards a Clear North, UNWTO, Madrid.

World Tourism Organization (2020a) Barômetro. Disponível em: https://www.unwto.org/es/news/el-turismo-retr ocede-a-niveles-de-1990-con-una-caida-en-llegadas-del-mas-del-70. Acesso em 21 de julho de 2021

World Tourism Organization (2020b) News. disponível em: https://www.unwto.org/es/news/covid-19-turismomundial-sigue-paralizado-mientras-el-100-de-los-paises-imponen-restricciones-a-los-viajes. Acesso em: 14 jun. 2021.

\section{Notas}

1 O Grupo de Pesquisa Turismo em Tempos de Pandemia da Universidade de São Paulo (USP) é certificado pelo CNPq e coordenado pela Prof ${ }^{a}$ Dra. Rita de Cássia Ariza da Cruz.

2 Dados fornecidos pela SEMFAZ para contemplar a entrevista realizada por meio eletrônico com o representante da Secretaria Municipal de Indústria, Comércio e Turismo de Aracaju (SEMICT), em 20 de março de 2021. 
3 Formulários aplicados através do Google Forms no período de março a maio de 2021.

4 Entrevista realizada através de e-mail com a Presidente do Sindicato dos Guias de Turismo de Sergipe no dia 22 de março de 2021.

5 “Turismo perde US\$ 4,5 trilhões em 2020, mas pode ter rápida retomada" Disponível em: https://www.panrotas.com.br/coronavirus/pesquisas-e-estatisticas/2021/03/turismo-perde-us-45trilhoes-em-2020-mas-pode-ter-rapida-retomada_180488.html. Acesso em 26 de julho de 2021.

6. "Ministro do Turismo aposta em retomada pós-pandemia e sugere criação de passaporte sanitário". Disponível em https://www.camara.leg.br/noticias/740904-ministro-do-turismo-aposta-em-retomada-pos-pandemia-e-sugerecriacao-de-passaporte-sanitario/. Acesso em 25 de julho de 2021.

7 O termo "necropolítica" faz referência à forma em que o Estado age desigualmente na distribuição de oportunidades vitais, ocasionando em arbitrárias decisões em torno daqueles que irão viver ou morrer, pautado no biopoder de controle das populações. Neste sentido, "[...] el fondo del asunto lo que importa no son las vidas, ni la soberanía sobre ellas sino la regulación de la muerte” (Silva \& Victorino R., 2020, p. 317). 